Discussion. Synovial cell sarcoma is an exceedingly rare tumor in the head and neck. Jernstrom ${ }^{1}$ described the first synovial cell sarcoma of the head and neck in 1954. Fewer than 50 cases have been reported since, and fewer than $10 \%$ of these have involved the larynx or hypopharynx. They are commonly seen as large, painless neck masses in young men. Encroachment on adjacent structures may result in dysphagia, hoarseness, or airway obstruction. These symptoms often arise late and portend a poorer prognosis.

When occurring in the head and neck, synovial cell sarcomas are thought to arise from pleuripotential stem cells without any association with a synovial structure. They spread by way of direct extension along muscular and fascial planes and are rarely associated with nodal metastasis. ${ }^{2}$ Pulmonary metastatic disease has been described in some $40 \%$ of patients with head and neck synovial cell sarcomas, a mean of 30.8 months after resection. ${ }^{3}$ Although no studies have definitively demonstrated tumor size or histologic grade as prognostic factors, delay in diagnosis and narrow surgical margins have been shown to worsen outcome. ${ }^{3}$

The histologic diagnosis of synovial cell sarcoma is according to the classic biphasic histologic pattern of spindle cells mixed with glandular and epithelial elements, along with positive immunohistochemical staining for vimentin and cytokeratin. Other tumors, such as malignant fibrous histiocytoma, carcinoid, rhabdomyosarcoma, mesothelioma, pulmonary blastoma, and malignant glandular schwannoma, constitute the differential diagnosis and in our patient were ruled out by clinical, morphologic, and immunohistochemical differences.

Optimal treatment for head and neck synovial cell sarcomas is wide surgical excision of the tumor without lymphadenectomy. ${ }^{2,3}$ There are no data supporting the use of adjuvant chemotherapy. Radiation therapy has been shown to improve local control of head and neck synovial cell sarcomas if given in doses greater than 50 $\mathrm{Gy}^{3}$

Our patient's tumor was diagnosed late despite the fact that he had respiratory symptoms of 3 years' duration. His physical and radiographic examinations have ruled out another primary tumor and have excluded metastatic disease to date. With local recurrences of head and neck synovial cell sarcomas and metastases occurring as late as 62 months after surgical resection, ${ }^{2,3}$ long-term follow-up with computed tomography of the neck and chest is probably indicated. This patient will be followed up with bronchoscopy and computed tomography of the neck and chest every 6 months for a minimum of 5 years.

\section{REFERENCES}

1. Jernstrom P. Synovial sarcoma of the pharynx: report of a case. Am J Clin Pathol 1954;24:957-6 I.

2. Roth JA, Enzinger FM, Tannengaum M. Synovial sarcoma of the neck: a followup study of 24 cases. Cancer 1975;35:1243-53.

3. Amble FR, Olsen KD, Nascimento AG, Foote RL. Head and neck synovial cell sarcoma. Otolaryngo Head Neck Surg 1992;107;631-7.

\title{
IMMOBILIZED INSTRUMENT FOR MINIMALLY INVASIVE DIRECT CORONARY ARTERY BYPASS: MIDCAB DOUGHNUT
}

\author{
Masao Takahashi, MD, Shinichiro Yamamoto, MD, and Shigeki Tabata, MD, Fukui, Japan
}

So that satisfactory vessel immobilization can be achieved, enabling consistently accurate grafting during off-pump coronary artery bypass grafting (CABG), mechanical immobilizing devices ${ }^{1-3}$ have been developed along with immobilization methods including pharmacologic control of heart rate to produce bradycardia ${ }^{2}$

From the Department of Cardiovascular Surgery, Fukui Prefectural Hospital, Fukui, Japan.

Received for publication Feb. 26, 1997; accepted for publication May 13, 1997.

Address for reprints: Masao Takahashi, MD, Department of Cardiovascular Surgery, Fukui Prefectural Hospital, 2-8-1 Yotsui, Fukui, 910, Japan.

J Thorac Cardiovasc Surg 1997;114:680-2

Copyright (C) 1997 by Mosby-Year Book, Inc.

$0022-5223 / 97 \$ 5.00+0 \quad \mathbf{1 2 / 5 4 / 8 3 4 1 5}$ and induction of transient ventricular asystole with adenosine. Even with heart rates of about 40 beats/min, however, the technical demands of suturing are often difficult. In this report, we describe a new immobilizing instrument for use during minimally invasive $\mathrm{CABG}$ on the beating heart. With this instrument, a motionless and bloodless operative field can be achieved without occlusion of the distal coronary artery. The use of this instrument facilitates the new techniques of operating on the beating heart.

Techniques. The instrument, called a MIDCAB doughnut, consists of a double-bottomed silicone rubber dome and a suction tube that is supported with a handle. It has a simple structure, and its elastic firm material is thought to be safe and secure. The elastic dome has a small hole (14 to $16 \mathrm{~mm}$ in diameter) at the center through which the coronary artery that is being anastomosed can be positioned. The dimensions of the dome 


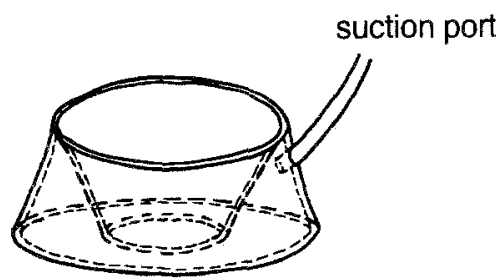

\section{MIDCAB doughnut}

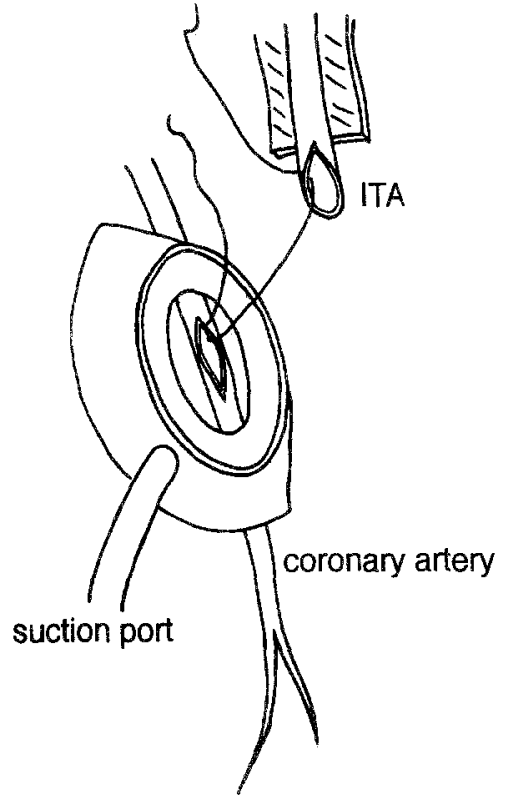

Fig. 1. Schema of the MIDCAB doughnut. ITA, Internal thoracic artery.

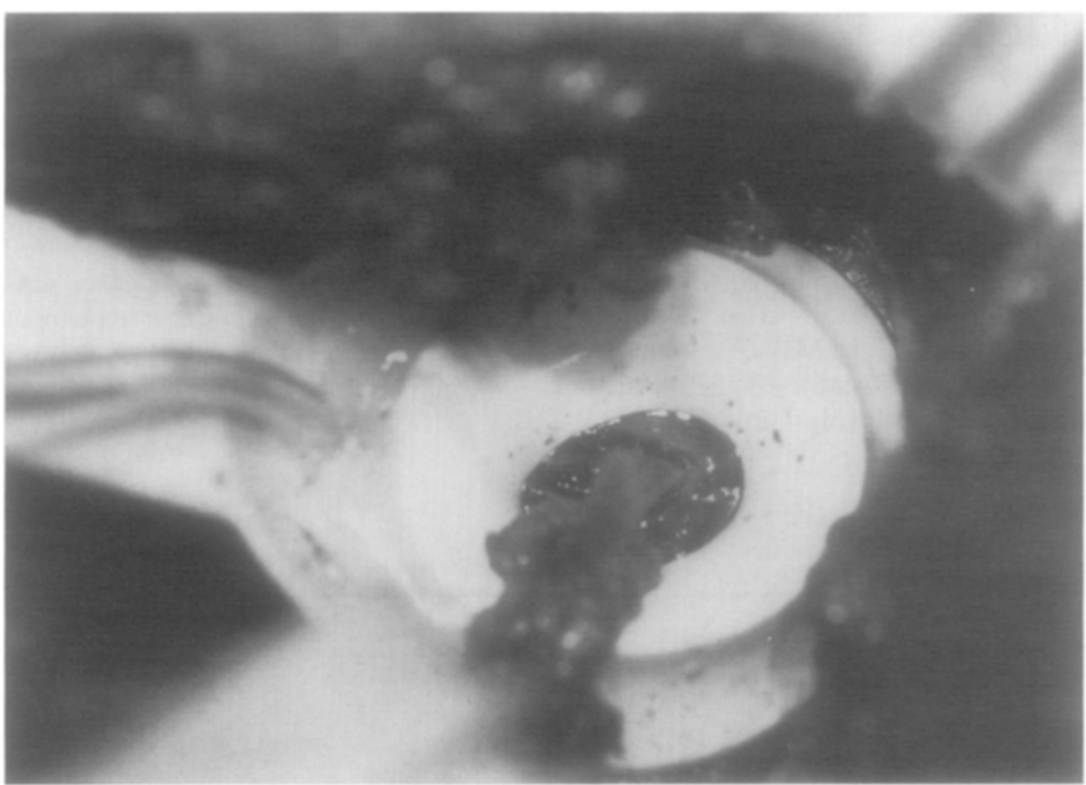

Fig. 2. The instrument was fixed to the heart by air suction. Both a motionless and bloodless operative field could be obtained with the use of this instrument.

are $36 \mathrm{~mm}$ in diameter and $10 \mathrm{~mm}$ in depth. The mechanism of fixation to the heart is negative pressure by air suction (Fig. 1).

After preliminary studies using four dogs and a pig, we have used the MIDCAB doughnut in three patients who underwent traditional $\mathrm{CABG}$. The heart was exposed through a median sternotomy. The MIDCAB doughnut was fitted over the epicardium around the anastomotic site of the left anterior descending artery (LAD) by air suction with a wall sucker. Stable immobilization of the LAD could be achieved on the beating heart. The epicardium and adipose tissue on the LAD were dissected by means of this technique. Pressure in the instrument was $-400 \mathrm{~mm} \mathrm{Hg}$. The instrument could be easily removed by releasing the negative pressure. Cardioplegic arrest was obtained in the ordinary way with the use of extracorpo- 
real circulation, and the $\mathrm{LAD}$ was then incised for grafting. The MIDCAB doughnut was applied again around the LAD. Bothersome bleeding from the anastomotic site was easily controlled without aortic venting. After removal of the instrument, the traces on the heart surface disappeared in a few minutes. Hemorrhagic lesions was never found in the suction sites. The instrument was easy to handle when being placed over and removed from the heart surface.

The instrument has been applied in seven patients at other institutes during minimally invasive $\mathrm{CABG}$ without the support of extracorporeal circulation. In all seven patients, the LAD was bypassed with a left internal thoracic artery (LITA) bypass graft. Through a small left anterior thoracotomy incision, the MIDCAB doughnut was fitted over the anastomotic site of the LAD by air suction. Through this minimal access approach, stable immobilization of the LAD could also be achieved on the beating heart. The LAD was occluded proximally with a tourniquet and then incised with a knife. The distal LAD was not occluded with a looping suture; however, bothersome back bleeding from the distal coronary artery was almost completely controlled by this technique. The anastomotic site could be firmly stabilized, and the LITA-LAD anastomosis could be precisely completed, just as with cardioplegic arrest (Fig. 2). After completion of the anastomosis, negative pressure was released and the MIDCAB doughnut was cut off and removed from the LITA graft. Postoperative coronary angiography showed that all the grafts were widely patent, and there were no stenotic lesions at the suction sites. In two patients, percutaneous transluminal coronary angioplasty to the circumflex artery was performed simultaneously, All seven patients were discharged uneventfully from the hospital and are doing well. In conclusion, this technical procedure can stabilize the artery and control bleeding, making the anastomosis easier.

Comment. A new instrument called a MIDCAB doughnut has been developed for immobilization of the anastomotic site and control of bleeding during minimally inva- sive $\mathrm{CABG}$. The instrument can make the operative field both motionless and bloodless without snaring. The mechanism of the instrument is based on a negative pressure with fixation to the heart surface around the anastomotic site. Potential problems of encircling snares, such as septal artery injury, atheromatous embolism, coronary artery transection, ventricular tear, or late stenosis of the native coronary, are avoided by use of this instrument. Negative pressure of the instrument occludes the coronary vessels to reduce or interrupt bothersome bleeding from the proximal or distal coronary artery. The need for the proximal encircling suture to be pulled up firmly for immobilization is lessened. An Octopus device (Medtronic, Inc., Minneapolis, Minn.) reported by Borst and associates ${ }^{4}$ is based on a principle similar to ours; the device consists of hard multiple suction domes. In their study, light microscopy showed small hemorrhagic suction lesions and intact endothelium of the coronary vessels, which traversed suction lesions, with a negative pressure under $-400 \mathrm{~mm} \mathrm{Hg}$. We believe that negative pressure fixation of the instrument to the heart may be superior to local myocardial compression methods.

\section{REFERENCES}

1. Westaby S, Benetti FJ. Less invasive coronary surgery: consensus from the Oxford meeting. Ann Thorac Surg 1996;62: 924-31.

2. Subramanian VA, Sani G, Benetti FJ, et al. Minimally invasive coronary bypass surgery: a multi-center report of preliminary clinical experience. Circulation 1995;92(Suppl):I645.

3. Boonstra PW, Grandjean JG, Mariani MA. Improved method for direct coronary grafting without CPB via anterolateral small thoracotomy. Ann Thorac Surg 1997;63:567-9.

4. Borst C, Jansen EWL, Tullenken CA, et al. Coronary artery bypass grafting without cardiopulmonary bypass and without interruption of native coronary flow using a novel anastomosis site restraining device ("Octopus"). J Am Coll Cardiol 1996; 27:1356-64.

\title{
MINIMALLY INVASIVE REDO AORTIC VALVE REPLACEMENT
}

\author{
Robert K. W. Tam, FRACS, R. Bruce Garlick, FRACS, and Aubrey A. Almeida, MBBS, Brisbane, Australia
}

From the Department of Cardiac Surgery, The Prince Charles Hospital, Brisbane, Australia.

Received for publication Feb. 18, 1997; accepted for publication May 28, 1997.

Address for reprints: Robert Tam, FRACS, Department of Cardiac Surgery, The Prince Charles Hospital, Rode Rd., Chermside, Brisbane, Australia, Q 4032.

J Thorac Cardiovasc Surg 1997;114:682-3

Copyright (C) 1997 by Mosby-Year Book, Inc.

$0022-5223 / 97 \$ 5.00+0 \quad \mathbf{1 2 / 5 4 / 8 3 5 6 2}$
A full resternotomy has been the standard approach for reoperation on the aortic valve. This carries a risk of right ventricular injury, which has a significant morbidity and mortality. ${ }^{1}$ Approaches to minimally invasive primary aortic valve replacement have been described. ${ }^{2,3}$ Our approach is to perform primary aortic valve surgery via a minimally invasive upper hemisternotomy without horizontal transection of the sternum. We describe a case of minimally invasive redo aortic valve replacement in which this approach was used.

A 69-year-old man had heart failure as a result of aortic valve xenograft degeneration. He had aortic valve replace- 